\title{
Institucionalidades do sistema de proteção social em linhas de fronteira:experiência metodológica e resultados obtidos
}

\author{
Institutionalities of the social protection system in border lines: \\ methodological experience and results obtained \\ Vera Maria Ribeiro Nogueira $^{1}$
Helenara Silveira Fagundes $^{* *}$
Daniela Castamann
Ineiva Terezinha Kreutz
}

\section{Resumo:}

Este texto apresenta o processo metodológico e os principais resultados de uma avaliação realizada para o Instituto Social do MERCOSUL (ISM) sobre os sistemas de proteção social em seis pares de cidades-gêmeas situadas nas fronteiras dos países do Mercado Comum do Sul (MERCOSUL). Com este intuito foram resgatadas informações sobre os dispositivos jurídicos e político-administrativos do MERCOSUL e Estados Parte, serviços, ações programáticas e demandas locais abrangendo os setores saúde, previdência social, educação e assistência social, cujos indicadores impactam negativamente as áreas de fronteiras internacionais do MERCOSUL. Em termos metodológicos utilizou-se a abordagem construída pela Comissão Econômica para América Latina e o Caribe para avaliar a institucionalidade das políticas sociais, a qual assinala quatro dimensões que concretiam o nível de cidadania em espaços regionais, nacionais e locais - a jurídico-normativa, organizacional, técnico-operativa e fiscal. Os resultados apontam em relação à dimensão jurídico-administrativa a lentidão na concretização das normativas e de acordos bilaterais entre os Estados Parte. Sobre a dimensão orgânico-ministerial destaca-se a forma distinta de organização pública nacional na proteção social nos países do bloco. Na dimensão substantiva as controvérsias em relação aos critérios de acesso de nacionais e não nacionais aos serviços no campo da saúde e proteção social foram frequentes, o que sinaliza para a divergência entre os gestores quanto ao grau de universalidade a ser obtido. Conclui-se que a abordagem metodológica utilizada favoreceu a construção do diagnóstico proposto favorecendo a elaboração de um plano de ação para superar os desafios identificados.

Palavras Chave: Cidadania. MERCOSUL. Fronteiras. Proteção social. Metodologia-avaliação.

\section{Abstract:}

This is text presents the methodological process and the main results of an evaluation carried out for the MERCOSUR Social Institute (ISM) on social protection systems in six pairs of twin cities located on the borders of the Southern Common Market (MERCOSUR) countries. To this end, information on

\footnotetext{
* Doutora em Enfermagem pela Universidade Federal de Santa Catarina. Professora adjunta do Programa de Pós-graduação em Política Social e Direitos Humanos da Universidade Católica de Pelotas E-mail: veramrn@gmail.com

** Doutora em Serviço Social pela Pontificia Universidade Católica do Rio Grande do Sul. Professora adjunto III da Universidade Federal de Santa Catarina do Departamento de Serviço Social. E-mail: hsfagundes@hotmail.com

*** Doutoranda, no Programa de Pós-Graduação em Serviço Social, da Universidade Federal de Santa Catarina. Docente no Curso de Serviço Social, da Universidade Estadual do Paraná (UNESPAR) - Campus Apucarana- PR.

**** Doutoranda da Universidade Federal de Santa Catariana (PPGSS/UFSC). Docente do Curso de Serviço Social da Universidade Estadual do Oeste do Paraná (UNIOESTE), Campus de Toledo/PR.
} 
MERCOSUR's and MERCOSUR's political and administrative mechanisms and states parties, services, programmatic actions and local demands covering the health, social security, education and social assistance sectors, whose indicators have a negative impact on the international borders MERCOSUR. Methodologically, we used the approach developed by the Economic Commission for Latin America and the Caribbean to evaluate the institutionality of social policies, which identifies four dimensions that concretize the level of citizenship in regional, national and local spaces - legal and normative, organizational, technical-operative and fiscal. The results point to the slow legal implementation of the regulations and bilateral agreements between the States Parties. On the organic-ministerial dimension, the distinct form of national public organization in social protection in the countries of the bloc stands out. In the substantive dimension, the controversies regarding the criteria of access of national and non-national to services in the field of health and social protection were frequent, which signals to the divergence among managers as to the degree of universality to be obtained. It is concluded that the methodological approach used favored the construction of the proposed diagnosis favoring the elaboration of a plan of action to overcome the challenges identified..

Keywords: Citizenship. MERCOSUR. Frontiers. Social Protection. Methodology-evaluation.

\section{Introdução}

Este texto apresenta o processo metodológico e os principais resultados de uma consultoria realizada para o Instituto Social do Mercosul - ISM, para avaliar os sistemas de proteção social em seis cidades gêmeas situadas nas fronteiras dos países do MERCOSUL. O estudo realizado teve como matriz orientadora a missão do ISM de tornar a dimensão social o eixo do processo de integração regional, buscando torna-lo solidariamente justo, igualitário e equitativo com a redução das assimetrias sociais que imperam na região. $A$ finalidade última atenderá a uma preocupação do ISM no sentido de contribuir, com suas ações, para materializar um conjunto de direitos fundamentais relativos ao Estatuto de Cidadania do MERCOSUL. Com este intuito foram estipulados como objeto do presente contrato as informações sobre os dispositivos jurídicos e político-administrativos do MERCOSUL e Estados Parte, serviços, ações programáticas e demandas locais em seis pares de cidades-gêmeas, a saber: Posadas-Ar/Encarnación-Py; Concordia-Ar/Salto-Uy; Puerto Iguazu-Ar/Ciudad del Este-Py/Foz do Iguaçu-Br; Guaíra-Br/Salto do Guairá-Py; Bernardo de Irigoyen-Ar/Dionísio Cerqueira-Br; Santana do Livramento-Br/Rivera-Uy.

Foram definidos para estudo os setores de educação, saúde, previdência social e proteção social/assistência social por comporem o núcleo duro da cidadania social. São também os setores cujos indicadores impactam com maior rigor as áreas de fronteiras internacionais do MERCOSUL, espaços geográficos marcados por altas taxas de desigualdade, carência de recursos de infraestrutura e dificuldade de acesso aos bens e serviços que compões a cidadania social. Destacam-se, nestes espaços, as desigualdades 
territoriais transfronteiriças, que se somam às desigualdades nacionais persistentes nos países da América Latina, compondo um quadro complexo em termos de desenvolvimento integral. Por esta razão, a situação destas cidades no âmbito da proteção social, objeto deste estudo, foi proposto para apontar os limites e as estratégias possíveis para tornar a dimensão social o eixo central do processo de integração regional.

Cabe ressaltar a tardia preocupação com a faixa de fronteira, para além do ideário da segurança nacional e do escoamento de produtos comerciais, o que produziu, como consequência, reduzidos estudos e leituras sobre esta realidade. A concepção de fronteiras internacionais esteve alheia à noção de territorialidade, redes de intersecção e como um espaço vivido particular. Devido ao ideário vigente até há pouco tempo, estes estudos focaram, especialmente, as dimensões físicas das fronteiras e, no aspecto cultural, como o lugar onde transitam os "estrangeiros", os "diferentes".

Os textos que privilegiam esta concepção de fronteira contribuíram para tornar invisível o mundo vivido pela população fronteiriça. Foi a partir dos processos de integração regional, em um primeiro momento decorrentes de motivação econômica com a preocupação de garantir a competitividade externa através do fortalecimento dos países que implementaram o MERCOSUL, que gradativamente, se passou a reconhecer a importância da dimensão social, e a considerar a fronteira como o primeiro degrau de integração. $E$, em um segundo momento, se passou a reconhecer não unicamente a relevância da dimensão social, como se passa a olhar a fronteira como o primeiro degrau de integração. Ou seja, um espaço onde as trocas de diversas ordens entre cidadanias distintas determinam um tipo de interação peculiar, construindo um espaço particular dependendo de suas trajetórias históricas e culturais.

Considerando o exposto acima e atendendo ao indicado no Termo de Referência contratual e no plano de ação proposto, o diagnóstico focalizou a funcionalidade real dos acordos binacionais e regionais. Ou seja, em que medida se supera o plano normativo e se concretiza a atenção às necessidades sociais aos residentes em fronteiras, e quais as indicações de estratégias para ultrapassar o formalismo que vem sendo anunciado em estudos sobre o tema visando oferecer serviços sociais. Foi exatamente por reconhecer do descompasso entre os dispositivos formais (regionais, nacionais) e as ações locais que se formulou o plano de pesquisa avaliativa. Portanto, as ações previstas procuraram, incluindo a pesquisa documental, dar voz aos sujeitos políticos locais enquanto atores competentes para elucidar qual seria o caminho mais indicado para estabelecer as pontes entre a 
normatividade legal e a fruição dos direitos. Contou com a participação de pesquisadores e alunos de Pós-Graduação da Universidade Católica de Pelotas, Universidade Federal de Santa Catarina, Universidade da Integração Latino-Americana, Universidade Nacional de Misiones (Argentina), Universidade Nacional de Assunção (Paraguai) e Universidade de La República (Uruguai). Destaca-se a contribuição ímpar dos professores e estudantes envolvidos, além da colaboração da Equipe de Pesquisa do ISM e da Secretaria do MERCOSUL.

\section{Direitos Sociais, Espaços Transfronteiriços e o Protagonismo dos Sujeitos Políticos Locais}

Pensar na cidadania social em espaços transfronteiriços significa pensar no mundo da vida, conforme afirmado anteriormente. É no mundo real que se define a maior ou menor garantia da fruição dos direitos definida pelo tipo de relação estabelecida entre EstadoSociedade Civil, no âmbito local. Esta garantia exige a operacionalização de políticas e programas que forneçam os bens e serviços previstos para nacionais e não nacionais. Exige políticas públicas e pressupõe, para sua implementação, um nível de institucionalidade marcado pela capacidade pública em planejar e executar ações, tendo a perspectiva democrática como norte a ser seguido (DI GIOVANNI; NOGUEIRA, 2015).

O âmbito municipal, é o espaço privilegiado na implementação das decisões políticas, situando-se como um ente político-administrativo onde as condições acima devem ser resguardadas. Torna-se, assim, uma questão relevante verificar em que medida a implementação dos dispositivos relacionais de ampliação de direitos são aprendidos e reconstituídos na implementação.

Outra questão central a ser pensada trata do protagonismo dos atores locais, sejam os gestores ou profissionais. Ou seja, os profissionais que estão na ponta dos sistemas de proteção social e que executam os programas concernentes a seu campo de ação. Um ponto em comum nas experiências analisadas em estudos anteriores (NOGUEIRA, 2011; NOGUEIRA, GIMÉNEZ; FAGUNDES, 2012), quando positivas, são sistematicamente decorrente das ações de alguns gestores mais afinados com a garantia universal do acesso aos bens e serviços de forma universal. Esses atores políticos não têm competências similares em todos os países devido a duas situações: as diferenças dos sistemas de proteção social e o grau de descentralização de cada país. 
Em faixas de fronteira se verifica que os sistemas locais de proteção social devem ser observados em duas dimensões - o lado organizativo de prestação de serviços e ações oferecidos e, de outro, a demanda de uma população que não é unicamente residente no espaço local, mas transita de ambos os lados da fronteira. Este trânsito expressa uma realidade a ser enfrentada pelos gestores, de onde se origina a exigência de cooperação entre os sistemas dos países limítrofes. Assim, a cooperação envolve a transferência, o movimento ou mudança entre indivíduos, serviços e recursos (GLINOS, 2011). Entretanto, a cooperação é bastante assimétrica, influenciada pela discricionariedade dos gestores, reduzindo ou mesmo anulando a possibilidade de atenção aos usuários dos sistemas residentes no espaço fronteiriço de outro país.

Ao se refletir sobre os sistemas locais de proteção social, duas dimensões relativas à fruição dos direitos sociais devem ser levadas em conta: os dispositivos relacionais e a implementação de políticas com ênfase no papel desempenhado pelos atores políticos locais.

A intencionalidade transversal ao relatório aborda as desigualdades territoriais ocorridas ao longo da linha da fronteira, as quais são incorporadas ao debate sobre o direito social. Estas desigualdades territoriais decorrem da distinção, em um mesmo território, de atenção desigual em educação, proteção social, saúde e previdência, não garantindo direitos igualitários entre os habitantes de um mesmo território contíguo.

\section{O Processo Metodológico}

O debate sobre como avaliar os estados de bem estar emergentes exige o apoio de metodologias de avaliação das políticas sociais que deem conta de resgatar as institucionalidades dos sistemas de proteção social construídos para fazer frente às desigualdades sociais ainda persistentes na América Latina. Com esta intencionalidade foi utilizada a abordagem construída pela Comissão Econômica para América Latina e Caribe (CEPAL, 2017; MARTÍNEZ, 2017) para avaliar a institucionalidade das políticas sociais na América Latina. A proposta cepalina assinala quatro dimensões a serem analisadas e as quais concretizam o nível de cidadania em espaços regionais, nacionais e locais - dimensões jurídico-normativos, organizacionais, técnico-operativas e fiscais - ultrapassando, assim abordagens lineares e focadas unicamente em resultados. 
A dimensão jurídica-normativa constitui a base legal da institucionalidade relacionada à garantia de direitos econômicos, sociais e culturais das populações adstritas a um Estado nacional. Se referem aos ordenamentos a partir dos quais vão se construindo as institucionalidades relativas as políticas estatais, vis a vis a cultura local, incorporando tanto a:

[...] dimensión central para identificar los compromisos de los Estados con la garantía de derechos económicos, sociales y culturales de las personas. Incorpora la adhesión y ratificación de convenios y tratados internacionales, la garantía de derechos y la presencia de distintas temáticas sociales en los textos constitucionales, así como en las leyes y normativas específicas. Por tanto, incluye las leyes sociales sectoriales, en especial desarrollo y protección social, como también los planes nacionales de desarrollo social (CEPAL, 2017).

A dimensão organizacional se refere ao aparato estrutural e de recursos humanos disponíveis e competentes no plano jurídico para implementar as políticas sociais, ou seja, os ministérios, secretarias e outras organizações formais instituídas para concretizar os planos, programas e projetos. A dimensão técnico-operacional, neste texto designada como dimensão substantiva, é constituída pela dinâmica processual relacionada à implementação da política social. Envolve a capacidade de planejamento e gestão das políticas e programas sociais. Pode ser comparado ao "recheio" da estrutura organizacional. Implica no uso ético e efetivo de ferramentas utilizadas na gestão das políticas sociais pelos sujeitos políticos em todos os níveis governamentais. É influenciada, igualmente, pelos níveis ministeriais ou interministeriais, ajustados às condições estruturantes locais. Envolve competência política e técnica dos atores políticos governamentais para conciliar os interesses distintos relacionados à implementação dos mecanismos de proteção social. A dimensão fiscal compreende os recursos financeiros utilizados para manter a dimensão organizacional e o custeio dos planos, programas e projetos.

A partir deste enfoque metodológico o estudo teve abrangência regional tendo sido realizado em seis pares de cidades gêmeas situadas na linha de fronteira dos países acima mencionados, tendo sido possível construir um diagnóstico sobre a efetividade dos acordos regionais na ampliação da cidadania social, ou seja, na satisfação das necessidades sociais. Os dados que subsidiaram a análise foram obtidos através de pesquisa documental junto à Secretaria do MERCOSUL e Ministérios dos países envolvidos e entrevista semiestruturada com os gestores e profissionais de saúde das cidades campos de estudo. 
A finalidade última deste estudo, ou seja, identificar a situação da proteção social na região de fronteira exigiu, em termos metodológicos procedimentos factíveis de identificar a institucionalidade social do tema tratado e, simultaneamente, indicar o gradiente de proteção social oferecido pelas políticas públicas, favorecendo a construção de um diagnóstico instrumental da região estudada. Alerta-se para a importância da funcionalidade dos propostos metodológicos, ou seja, a proposição de ações para reduzir as assimetrias fronteiriças com vistas a atenuar as desigualdades na fruição dos direitos propiciando um patamar equalizado de cidadania para toda a população residente no espaço territorial do MERCOSUL.

Por esta razão adotou-se a diretiva da CEPAL (2017), para se avaliar a institucionalidade social das políticas de proteção social - os elementos jurídico-normativos, organizacionais, técnico-operativas. Não se incorporou os elementos fiscais, tanto pela não transparência destes dados como pela impossibilidade de acesso aos responsáveis pelo exíguo tempo para esta atividade, o que demandaria viagens e permanência nas capitais dos países. A preferência por utilizar esta proposta decorre de estudos anteriores realizados na franja fronteiriça, os quais sinalizam a relevância da articulação destes elementos, pois resgatam o sugerido por Costa, Silva e Biasoto (2008) sobre as políticas públicas. Pode parecer óbvio que o sucesso das políticas ou programas se deva a uma conjunção de fatores, cuja ocorrência simultânea provoca uma espécie de sinergia que encaminha algumas intervenções em direção a seus objetivos.

No caso estudado foi possível averiguar onde se localizam as desigualdades territoriais considerando-se a diversidade normativa dos países, expressas desde a atribuição de cidadania (jus solis e jus sanguinis), a incorporação na ordenação jurídica de acordos e protocolos internacionais, as competências jurídicas em formalizar acordos bilaterais ou trilaterais pelos entes subnacionais, a regulação sobre migração até a delimitação da faixa de fronteira (oscilando entre 20 e $150 \mathrm{~km}^{2}$ ). Além, e por conta da desigualdade territorial, outras desigualdades adquirem relevo na fronteira, aprofundando as relacionadas ao gênero (prostituição, violência contra a mulher), exploração do trabalho infantil e os mulas ou laranjas ${ }^{2}$, étnicas (dificuldades identitárias e preconceitos raciais). A partir desta concepção é que se definiu a importância do resgate das normativas internacionais, legislações nacionais e acordos bi e trilaterais existentes e incidentes nos países sobre a franja fronteiriça e também com incidência indireta na região.

\footnotetext{
${ }^{1}$ Como mulas ou laranjas são designadas as pessoas que transportam mercadorias ilícitas através da fronteira.
} 
Entende-se que os itens acima viabilizam avaliar o que se convencionou designar, na literatura política, de Estado em ação. Alterações no quadro fronteiriço exigem a intervenção estatal para além do plano discursivo formal, viabilizando à concretização de planos, programas e projetos incidentes sobre situações a serem alteradas.

A base jurídico-normativa é uma ferramenta poderosa para equalizar a cidadania social, mas insuficiente, na maioria das vezes, para a materialização dos planos, programas e projetos, sendo que a situação não se altera, especialmente levando em conta a democracia de baixa intensidade da maioria dos países latino-americanos. Nesta direção, o segundo elemento apontado pela CEPAL para estudo da realidade local - a dimensão organizacional é igualmente relevante, pois estabelece o trânsito entre a base normativa e a possibilidade material e estrutural das propostas programáticas em distintas instâncias governamentais. Diz respeito à configuração dos ministérios e instâncias do poder executivo competentes para implementar os programas de carácter social, a partir de seus mandados decorrentes da situação jurídica. A estrutura orgânica dos ministérios, secretarias, departamentos e municípios exigem uma autonomia mínima, especialização, relação e importância face as demais áreas setoriais do governo (MARTíNEZ; VALERA, 2017). Entendendo a relação entre ministérios e municípios é que se buscou apreender a conformação dos primeiros direcionando à política local.

O elemento organizacional é acompanhado do que a CEPAL designa como a dimensão técnico-operativa, também designada como a dimensão substantiva, no sentido que materializa concretamente a proteção social. A literatura atual sobre políticas em regiões fronteiriças dá conta da relevância destes atores. Quando imbuídos de uma perspectiva de cidadania democrática e competentes para manejar a "caixa de ferramentas" jurídico administrativas a sua disposição têm provocado alterações significativas em distintos níveis ${ }^{3}$. Esta dimensão diz respeito aos atores, normas e elementos institucionais envolvidos com a implementação e gestão, tanto em nível interministerial como subnacional (CEPAL, 2017; MARTÍNEZ; VALERA, 2017). O peso deste elemento, em áreas de fronteira, vai além do poder local atravessando os limites internacionais e impõe a capacidade de articular os atores chave do outro lado da fronteira.

\footnotetext{
2 Estudo comparativo realizado entre Espanha, Portugal, França e entre Brasil, Uruguai e Paraguai demonstram a importância dos sujeitos políticos subnacionais, alterando mesmo normativas da União Europeia (JIMÉNEZ; NOGUEIRA, 2009).
} 
Por fim, a quarta dimensão é a fiscal, referente aos custos para manutenção das demais dimensões, ou seja, para as instalações e recursos humanos para o funcionamento da estrutura jurídico-normativa, organizacional e técnico operativa. Operam nesta, para análise do grau de proteção, os recursos mobilizados para o desenvolvimento social em termos de prioridades, estabilidade e garantia de seguimento. Observa-se que a visibilidade dos gastos públicos não é fácil de ser obtida por três razões. A primeira é a incipiente organização técnico-administrativa na manutenção de canais viabilizadores de consultas públicas (publicação sistemática por distintos meios, como web e publicações periódicas). A segunda é a linguagem hermética utilizada nas contabilidades estatais, favorecendo à apreensão unicamente por pessoal altamente especializado, o que interdita um controle destes gastos pela maioria da população. A terceira é a reduzida evidência da utilização dos recursos pelos níveis subnacionais. Esta distinção faz com que, em regiões de fronteira, com municípios pequenos, a organização contábil se encerre em nível estadual ou departamental ${ }^{4}$.

A partir das dimensões acima sumariadas, as estratégias metodológicas foram encaminhadas no sentido de favorecer a identificação jurídico-formal do aparato de proteção social, as estruturas organizacionais disponíveis, a concretude das propostas de proteção (demandas, serviços, acesso e acessibilidade) e os recursos fiscais. Estas dimensões são potencialmente viáveis para se produzir um diagnóstico que permita eleger linhas programáticas futuras visando materializar e concretizar direitos.

O resgate da institucionalidade social, neste estudo, buscou verificar os seguintes tópicos: indicações do MERCOSUL no campo da proteção social; garantias legais no plano dos direitos sociais em cada uma das áreas; coerência entre a formulação e a execução das ações propostas dando concretude às intencionalidades dos dispositivos legais e programáticos; mecanismos de pactuação e resolução de situações emergenciais; dinâmica da integração evidenciada nos fluxos/ periodicidades e nas garantias de acesso e integralidade da atenção.

Os procedimentos metodológicos foram determinados pela compatibilização entre objetivos e metas e o tempo disponível para a coleta das informações. Por esta razão foram privilegiados os dados secundários, a saber: produções acadêmicas sobre o objeto de estudo; os bancos de dados de pesquisas realizadas nas cidades escolhidas como campo de

\footnotetext{
${ }^{3}$ A dimensão fiscal não será abordada neste trabalho devido à complexidade na obtenção de dados em relação ao tempo isponível para obtenção dos dados.
} 
pesquisa; sítios da web e documentos públicos dos entes envolvidos com a proteção social nos quatro setores pesquisados. A dimensão técnico-operativa foi resgatada através de entrevistas com pesquisadores que construíram os bancos de dados (saúde e assistência) e, ainda, com os gestores dos quatro setores nas cidades gêmeas.

\section{Etapas do Estudo}

a) Primeira Etapa - Em um primeiro momento foram articuladas as cooperações institucionais compreendendo a formalização de pactos informais com os pesquisadores quem vem realizando estudos sistemáticos sobre questões fronteiriças e integrantes de um grupo de pesquisa que há dez anos vem se dedicando ao tema.

O segundo momento desta primeira etapa foi dedicado à seleção de textos de referência teórica que orientariam não apenas 0 desenho mais detalhado dos procedimentos, incluindo aqui a construção dos instrumentos de coleta de informações.

A construção dos roteiros para coleta dos dados foi realizada com participação presencial dos professores em Florianópolis e em Pelotas e encaminhado para os demais pesquisadores para contribuição e complementação do mesmo. Foram construídos os seguintes instrumentos:

I. Quadro com os dados básicos dos municípios para comporem os dados contextuais, sendo estes: extensão em $\mathrm{Km}^{2}$, total de habitantes, habitantes em zona rural, habitantes em zona urbana, cidade gêmea, país de fronteira, índice de desenvolvimento humano, salário médio mensal e domicílios com renda per capita abaixo de meio salário mínimo. A seleção dos municípios foi feita por ocasião da elaboração da proposta para concorrer a convocatória e se pautou nos seguintes critérios: cidades pertencentes a cada um dos países do MERCOSUL, população, porte do município, tipo de fronteira (geográficos), referência de sinapse transfronteiriça - incipiente, média e alta ${ }^{5}$. Dois pares de cidades gêmeas foram indicadas pelo ISM: Salto/Concordia e Posadas/Encarnación.

A tipologia de classificação do porte dos municípios foi baseada na indicação da Política Nacional de Assistência Social (PNAS) do Ministério de Desenvolvimento Social do Brasil (BRASIL, 2004). Para efeitos de caracterização do porte dos municípios, a PNAS os

\footnotetext{
${ }^{4}$ Com base em estudos realizados anteriormente pelo Grupo de Pesquisa e conceitualmente sinapse se refere as trocas entre as cidades gêmeas e as fronteiras, ou seja, o grau de integração dos espaços fronteiriços.
} 
classifica em cinco grandes grupos: Municípios de Pequeno Porte I (até 20.000 hab): Bernardo de Irigoyen e Dionísio Cerqueira; Municípios de Pequeno Porte II (20.001 a 50.000 hab.): Posadas, Guaíra e Salto do Guairá; Municípios de Médio Porte (50.001 a 100.000 hab): Puerto Iguazu, Encarnación e Santana do Livramento; Municípios de Grande Porte (100.001 a 900.000 hab.): Foz do Iguaçu, Concordia, Salto, Rivera e Ciudad del Este. São consideradas Metrópoles as cidades com mais de 900.001 habitantes.

Quadro 1 - Dados Demográficos das Cidades Gêmeas ${ }^{6}$

\begin{tabular}{|c|c|c|}
\hline PAÍS & MUNICÍPIO & HABITANTES \\
\hline \multirow{4}{*}{ Argentina } & Puerto Iguazu & 42.849 hab \\
\hline & Bernardo de Irigoyen & 13.768 hab \\
\hline & Posadas & 277.564 hab \\
\hline & Concordia & $170.033 \mathrm{hab}$ \\
\hline \multirow{4}{*}{ Brasil } & Guaíra & 30.704 hab \\
\hline & Foz do Iguaçu & $256.088 \mathrm{hab}$ \\
\hline & Dionísio Cerqueira & 14.811 hab \\
\hline & Santana do Livramento & 82.464 hab \\
\hline \multirow{3}{*}{ Paraguai } & Salto do Guairá & 33.444 hab \\
\hline & Ciudad del Leste & 387.755 hab \\
\hline & Encarnación & 93.497 hab \\
\hline \multirow[t]{2}{*}{ Uruguai } & Salto & $124.861 \mathrm{hab}$ \\
\hline & Rivera & $103.493 \mathrm{hab}$ \\
\hline
\end{tabular}

Fonte: dos Autores.

II. Instrumentos de pesquisa: para coleta de dados jurídico-normativos, dados posteriormente organizados em um quadro para cada um dos países e por setores pesquisados.

III. Construção de quadros para levantamento de dados sobre produção científica, grupos de pesquisa, leis e normativas, dissertações e teses sobre questões fronteiriças no âmbito da educação, saúde, proteção e previdência social.

IV. Construção do roteiro de entrevistas com os gestores das localidades escolhidas e articulação e capacitação dos seis pesquisadores de campo.

b) Segunda etapa - Compreendeu a coleta dos dados com a seguinte sistemática de trabalho. A realização das entrevistas foram coordenadas pelas professoras pesquisadoras

\footnotetext{
${ }^{5}$ Os dados demográficos da Argentina são do IDEC, do Brasil do IBGE, do Uruguai e Paraguai de Poblacion.city.
} 
em Florianópolis, Pelotas, Foz do Iguaçu, Montevidéu e Posadas. Foram entrevistados os gestores das quatro áreas, profissionais e técnicos indicados pelos gestores como competentes para informar as questões objeto da entrevista.

c) Terceira etapa - Sistematização material coletado Para a elaboração do diagnóstico foram consultadas livros, teses, artigos e documentos governamentais (atas de reuniões das Comissões de Fronteira).

\section{Realidade Social das Fronteiras Internacionais do MERCOSUL}

A cidadania social nas regiões de fronteira é um tema com inserção recente nas agendas governamentais e não-governamentais e expressa uma variedade de sentidos decorrente da postura ética e política dos sujeitos coletivos envolvidos com seu alcance, garantia e fruição. Constata-se, compreensivelmente, a centralidade do debate sobre os aspectos políticos inerentes à ampliação e garantia dos direitos sociais, visto seu impacto direto sobre o ponto nodal das políticas públicas de corte social, ou seja, a universalidade da proteção social.

O diagnóstico sobre a institucionalidade da proteção social nas fronteiras foi elaborado obedecendo as dimensões relacionadas à concretização das políticas sociais elencadas inicialmente, e que orientaram a coleta dos dados, a saber, a dimensão jurídicoadministrativa, compreendendo as normativas do MERCOSUL como os acordos bilaterais ou multilaterais para as áreas privilegiadas para o estudo; a dimensão orgânico-ministerial, incorporando a estrutura dos ministérios e instâncias do poder executivo nacional, estadual e local e a dimensão substantiva, incluindo um breve contexto das cidades gêmeas, os serviços prestados, a configuração e incorporação da demanda de usuários nacionais e não nacionais, incluindo os desafios e proposições com vistas a ampliar a cidadania social na região estudada.

Em termos gerais, a primeira observação, ao se comparar o contexto dos países e o impacto na região fronteiriça, é a assimetria em termos de área geográfica, população, economia e divisão jurídico-administrativa entre outros aspectos. A área geográfica determina a maior ou menor distância da linha da fronteira dos centros administrativos federais e de centros urbanos com equipamentos de proteção social e saúde mais qualificados e adequados. Devido a este fato, é observada uma desigualdade territorial em relação à cidadania social, sendo este um aspecto a ser pensado em termos de proposições 
estratégicas, através do fomento à cooperação entre os países na linha fronteiriça ou em investimentos para reduzir o déficit de equipamentos e recursos.

A ocupação populacional dos países é outra variável a pesar nas análises e diagnósticos sobre fronteira visto que um país com população indígena expressiva como o Paraguai, a densidade populacional centrada, majoritariamente na capital, caso do Uruguai e ainda a baixa densidade da população na linha da fronteira, caso de Argentina e Brasil, têm consequências na formulação e decisão sobre políticas públicas para a região.

A divisão jurídico-administrativa, ou seja, como se apresentam as organizações públicas é outro componente estrutural a ser levado em conta na definição de ações prioritárias. Um país com uma organização ministerial mais centralizada ou descentralizada, com níveis de competência distintos entre os entes subnacionais e formas de envolvimento da população nos debates para formulação de agendas públicas implicam em formas de abordagens diferenciadas no que se refere a iniciativas estratégicas. Estes aspectos, distintos em conjunto, ao fim e ao cabo, se traduzem inúmeras vezes em iniciativas locais, além da diplomacia formal, situando-se como a paradiplomacia verificada neste estudo, expressa nos acordos informais realizados entre gestores e profissionais das cidades gêmeas. Estes acordos paradiplomáticos, decorrentes da articulação tanto dos governos subnacionais como de entidades privadas tem significado a expansão das iniciativas externas dos países e incidido sobre ações no campo da proteção social e atividades culturais e econômicas (DESIDERÁ NETO; PENHA, 2016).

Entretanto, impacta com maior rigor, no plano local, a cultura política dominante no país e consequentemente nas suas fronteiras, compreendo o patamar de cidadania civil e social vigente expresso na igualdade e justiça como valores a serem perseguidos. Neste estudo, confirmados por outros realizados, os atores locais são os elementos chave para o êxito, fracasso, alcance e direcionamento para os valores de igualdade e justiça. A forma como estes atores articulam as forças políticas na resolução dos problemas locais parece ser um dos determinantes centrais a ser levado em conta ao se pensar em propostas de ação em cidades gêmeas ${ }^{7}$.

\footnotetext{
${ }^{6}$ Conforme anunciado anteriormente, as normativas relacionadas ao Mercosul foram obtidas no site http://www.mercosur.int/innovaportal/v/4059/2/innova.front/normativa-y-documentos-oficiales entre agosto e setembro de 2017. Observa-se que a decisões e recomendações coletadas foram unicamente as concernentes à proteção social, saúde, educação e previdência social.
} 


\section{Dimensão Jurídico Normativa}

Como primeiro passo em direção à cidadania social ressalta-se a relevância da decisão do Conselho do Mercado Comum (CMC) 18/99 ao dispor sobre o trânsito transfronteiriço. Entretanto, a lentidão em sua concretização, devido a necessidade de acordos bilaterais entre os Estados Parte, não concorreu para efeitos positivos no campo social em determinadas áreas, principalmente na proteção social e saúde. Por exemplo, para a fronteira Argentina/Brasil, a decisão foi internalizada no Brasil pelo Decreto no 8636 de 13 de janeiro de 2016. Na fronteira Brasil/Uruguai o Decreto $n^{\circ} 5.105$ que normatiza o acordo na ordem jurídica brasileira é de 14 de junho de 2004. Mesmo assim a Carteira de Trânsito Vicinal Fronteiriço (CTV), prevista neste acordo, não é mencionada pelos gestores e profissionais, neste e em outros estudos, como facilitadora do livre trânsito, exceto pelos entrevistados no Uruguai. Identificou-se que a população economicamente vulnerável ao buscar serviços de saúde e proteção social nas cidades vizinhas encontra dificuldades em obter este documento, uma vez que há a exigência de alguns requisitos difíceis de serem cumpridos, como o comprovante de residência. Anteriormente havia a cobrança de uma taxa, suprimida após negociações nos Encontros de Integração de Fronteiras, promovidos pelo Ministério de Desenvolvimento Social do Uruguai entre 2006 e 2009.

As decisões e recomendações, tanto do MERCOSUL como os acordos bilaterais, foram mencionados apenas pelos entrevistados da fronteira Uruguai, o que sinaliza para a insuficiência de informações que poderiam suscitar ações locais para ampliar e garantir serviços para os nacionais e os não nacionais.

As normativas existentes, do MERCOSUL e dos Acordos Bilaterais, que tem como objeto a educação tiveram maior êxito, através das Escolas bilíngues ou trilíngues, da educação técnica, da similitude entre os critérios de acesso à educação básica e média, na ênfase em atividades culturais integradoras, na ausência de critérios para acesso (é exigido apenas o histórico escolar) e especialmente na universalização do atendimento. Destaca-se serem as normativas sobre educação uma das mais antigas no bloco, datando de 1994 e 1996. A concretização destas normativas parece ser decorrente de uma predisposição dos gestores na região fronteiriça para cooperação e em alguns casos de integração na política de educação, especialmente na fronteira entre Brasil e Uruguai. Tal predisposição, ainda que não seja intencional e consciente, pode ser identificada nas falas dos sujeitos entrevistados da pesquisa e na utilização de instrumentos legais, criados no âmbito do MERCOSUL, como 
os parâmetros de equivalência para harmonizar os sistemas educacionais. Os gestores de educação, com raras exceções, manifestam a expectativa de resguardar a educação como um direito de todos evidenciando a centralidade dessa política no âmbito das regulamentações institucionais do MERCOSUL, como um direito universal e de aplicabilidade imediata, como uma meta ser seguida, ainda que se considere as disparidades, econômicas, culturais e regionais entre as cidades gêmeas e os países.

Dois Acordos se destacam entre Brasil e Uruguai, o Acordo sobre Localidades Vinculadas e o relativo à regulação para fixação de residência, ressaltados favoravelmente pelos gestores das cidades gêmeas do Uruguai. A regulação para fixação de residência na linha da fronteira não pode ser pensada de forma similar a uma transferência residencial de média e longa duração em outros espaços nacionais. A população vulnerável economicamente, e setores populacionais da classe média da região estudada, fixam residência onde o preço do aluguel dos imóveis é menos oneroso, mudando-se para outro lado da linha fronteira, quando há uma elevação de preços no local de residência. Este fato leva às inúmeras consequências nos demais setores, ou seja, na educação, a transferência frequente das crianças é uma das explicações para a evasão escolar na tríplice fronteira, relatada por todos os entrevistados; na saúde, tanto interfere no acesso aos sistemas sanitários como leva ao abandono de tratamento de doenças crônico-degenerativas ou infecto-contagiosas que exigem um acompanhamento contínuo. Esta última consequência é agravada pela fragilidade de ações cooperadas entre os sistemas locais de saúde no quesito referência e contra referência. Esta fragilidade se deve, na maior parte das situações, em face de alterações políticas nos governos locais, principalmente nas cidades brasileiras.

A inexistência de acordo sobre trânsito transfronteiriço com o Paraguai coloca este país em situação desvantajosa em relação aos demais, ocasionando situações problemáticas, especialmente na região da tríplice fronteira, pois quando a Ponte da Amizade é fechada como estratégia de protesto em face de medidas tomadas pelos entes nacionais, impossibilita o acesso de trabalhadores dos dois lados da fronteira.

Chama a atenção, a partir de 2010 até 2015, a forte ênfase das normativas relacionadas ao setor de proteção social, entendida aqui em seu sentido amplo, indo desde a proteção a segurança migratória, acesso à justiça, o cuidado com a criança e ao adolescente, a redução da desigualdade, a violência de gênero até proteção ao trabalho infantil, tráfico de mulheres e crianças e garantia dos direitos humanos. Estas decisões e recomendações coincidem com um período em que estes temas tiveram grande visibilidade e foram 
incluídos nas agendas governamentais nacionais, o que parece ser decorrência de dois fatos: a movimentação intensa de organizações da sociedade civil e a abertura de governos nacionais dos Estados parte para inclusão destes temas na agenda pública.

No setor saúde, outros documentos elaborados para favorecer a equiparação de direitos no espaço do MERCOSUL, como o Estatuto da Cidadania e o Plano de Ação Social, não foram pontuados pelos entrevistados, o que sinaliza, ainda, para seu desconhecimento. Nesta linha uma avaliação do resultado efetivo destes acordos e documentos, com a cooperação das cidades gêmeas, seria extremamente oportuna.

\section{Dimensão Orgânico-Ministerial}

Uma primeira observação sobre esta dimensão é a forma distinta de organização pública nacional na proteção social nos países do bloco, com rebatimentos significativos na região fronteiriça. A distinção é notadamente evidente desde os pressupostos que orientam as ações até as institucionalidades construídas a partir dos mesmos.

Outra questão relevante para a ampliação da cidadania social é o nível de competência dos entes federados subnacionais para estabelecer ações bilaterais, as quais esbarram em dificuldades de toda ordem, especialmente as relativas às formas de pagamento de serviços prestados em um outro país, a existência de acordos informais que não tem continuidade pela impossibilidade de formalização pelos municípios e departamentos, com exceção da Argentina, os trâmites burocráticos para prestação de serviços de profissionais são responsabilidade federal. Em decorrência desta impossibilidade, as experiências de cooperação com possibilidade de se firmarem e garantir a sua continuidade são interrompidas ao sabor das mudanças nos quadros gestores, como ocorreu em Bernardo Irigoyen, Dionísio Cerqueira e Barracão. Esta experiência partiu de iniciativas de profissionais de saúde e antecipava uma cooperação mais efetiva. Cessou por ocasião da troca do gestor de Dionísio Cerqueira, embora pareça que a ideia original tenha permanecido e atualmente as cidades desta região fronteiriça estão com outra iniciativa a ser acompanhada que é a do Consorcio Intermunicipal de Fronteira.

Outro aspecto é a constatação da distância entre a intencionalidade dos acordos e o desconhecimento dos trâmites e situação legal dos mesmos nos países, em decorrência de ausência de mecanismos de informação mais ágeis, aliado a distância da linha de fronteira das capitais. Este hiato tem uma contrapartida a partir das cidades fronteiriças, evidenciada 
na fala dos gestores da não incorporação de suas demandas pelas agendas governamentais. Há que observar que as requisições constadas pelas cidades em linha de fronteira, muitas vezes destoam do que é articulado entre os países, sendo que a institucionalização de políticas coordenadas e harmonizadas, na região de fronteira, exigiria um espaço comum de debates. O nível de integração entre as cidades gêmeas é distinto, sendo que, por exemplo, em Rivera e Santana do Livramento, pela história de cooperação, viabiliza avançar em mecanismos de cooperação, enquanto em outras cidades haveria que se pensar em harmonização de alguns serviços, como ocorre na área da educação, que é o setor no qual a harmonização é mais efetiva.

A educação é a área onde se identifica a convergência entre os princípios orientadores e a perspectiva inclusiva da população nacional e não nacional nos sistemas de ensino. O que não significa a ausência de crianças e jovens sem acesso à educação formal, como consequência tanto de desigualdades territoriais (população rural), econômicas (ausência de recursos de infraestrutura e custeio para as instituições de ensino) como étnicas (população indígena). Estas desigualdades devem ser repensadas nos planos nacionais devido aos seus desdobramentos futuros. Mesmo assim parece ter sido a área de maior convergência de resultados positivos entre os países.

Em todos os países do bloco os níveis de educação compreendem a educação infantil, a educação fundamental, ensino médio e a educação superior, sendo responsabilidade do governo central a reitoria do sistema. Destaca-se, nesse âmbito, a preocupação do governo paraguaio com a educação bilíngue, favorecendo desta maneira a população indígena e preservando os valores culturais do país.

A área da saúde apresenta aspectos interessantes, como uma identidade de princípios em relação a ser preocupação dos governos nacionais, veem o direito à saúde como um direito à vida. $\mathrm{O}$ atendimento universal entre nacionais e não nacionais em situações de urgência e emergência e, via de regra, um atendimento inicial na atenção básica, mesmo que após este primeiro atendimento se encaminhe a pessoa para o seu estado nacional em casos de não residentes. Parece ser a área mais complexa em relação a forma de organização político-administrativa dos serviços oferecidos, o que impacta consideravelmente em iniciativas de cooperação transfronteiriça.

No Uruguai se inicia uma descentralização paulatina dos serviços para os níveis subnacionais, enquanto no Brasil, a prestação de serviços é responsabilidade dos municípios, com algumas exceções para tratamento de alta complexidade e alguns insumos 
farmacêuticos. Na Argentina, embora o sistema seja considerado universal, há um programa não contributivo mantido pelo setor público assegurando o atendimento materno-infantil e acesso aos medicamentos essenciais. E ainda os trabalhadores do setor formal e do setor público nacional contam com a cobertura de instituições de seguridade social - as obras sociais. No Paraguai há a convivência de serviços oferecidos pelas instâncias nacionais e municipais e o setor público subdivide-se entre o Ministério de Salud Pública y Bienestar Social (MSPyBS), o Intituto de Previsión Social (IPS), a Sanidade Militar, a Sanidade Policial, a Universidade Nacional de Assunção e a Itaipú Binacional e Yacyretá (ALUM; BEJARANO, 2011). Esta fragmentação concorre para o resultado pouco efetivo, embora a legislação que regula o setor aponte possibilidades de superação.

Ademais das distinções acima indicadas, há no setor saúde, uma heterogeneidade decorrente do tamanho das cidades e da capacidade instalada de serviços. As cidades que conformam a tríplice fronteira: Posadas, Santana do Livramento e Rivera tem maior densidade populacional, oferta de serviços mais especializados, enquanto nas demais cidades, de médio e pequeno porte, há um déficit tanto de atenção em todos os níveis como a precariedade de recursos humanos, de fatores que são condicionamentos básicos para se pensar a prestação de assistência pública em saúde.

A maior discrepância identificada na linha da fronteira encontra-se nas premissas e estruturas de proteção social. Na Argentina a proteção social focaliza as vulnerabilidades por situação de pobreza, gênero e idade. A fragmentação da atenção começou a ser atenuada a partir da criação, em 2002, do Ministério de Desarrollo Social, com três grandes linhas de ação: economia social, política alimentar e vulnerabilidade familiar. Segundo Lucero (2017) se distingue nas últimas décadas duas diferentes estratégias de intervenção do Estado no âmbito da proteção social. A primeira dirigida aos trabalhadores desempregados e suas famílias, combinando de maneira particular a questão do Trabalho e da Assistência Social, sendo o maior destaque o Plan Jefas y Jefes de Hogar, desenvolvido entre 2002 e 2009. Uma segunda tendência aparece em meados da década de 2000 e se inicia a implementação de:

[...] intervenciones en las que instituciones creadas bajo la lógica del seguro social, se transforman para incluir entre sus destinatarios a trabajadores informales y desocupados. Tal es el caso de la Asignación Universal por Hijo (AUH en adelante) que tendrá un alcance e impacto considerable (LUCERO, 2017, p. 652). 
No Brasil a proteção social no âmbito da assistência social organiza-se sob forma de Sistema Único de Assistência Social (SUAS), assegurando o direito da população que dela necessitar (BRASIL, 2004). O SUAS organiza as ações em níveis de proteção social: i) Proteção Social Básica que desenvolve programas, projetos, serviços e benefícios a indivíduos e famílias em situação social vulnerável; e ii) Proteção Social Especial, dividida em Média e Alta Complexidades, com programas, projetos e ações junto às famílias com direitos violados devido ao abandono, maus-tratos, abuso sexual, uso de drogas entre outros. Enquanto, um Sistema é constituído pelas instâncias nacional, estaduais e municipais sendo de competência deste último a materialização das proteções legais, organizados por dois níveis de complexidade. A partir de 2009, com a Tipificação Nacional dos Serviços Socioassistenciais, aprovada pela Resolução no 109/CNAS, de 11 de novembro de 2009 (BRASIL, 2014), os serviços de proteção social são organizados por níveis de complexidade.

O nível de Proteção Social Básica atende: a) Serviço de Proteção e Atendimento Integral à Família (PAIF); b) Serviço de Convivência e Fortalecimento de Vínculos; c) Serviço de Proteção Social Básica no domicílio para pessoas com deficiência e idosas. Na Proteção Social de Média Complexidade são ofertados: a) Serviço de Proteção e Atendimento Especializado às Famílias e Indivíduos; b) Serviço Especializado em Abordagem Social; c) Serviço de Proteção Social a Adolescentes em Cumprimento de Medida Socioeducativa de Liberdade Assistida (LA), e de Prestação de Serviços à Comunidade; d) Serviço de Proteção Social Especial para Pessoas com Deficiência, Idosas e suas Famílias; e) Serviço Especializado para Pessoas em Situação de Rua. A Proteção Social de Alta Complexidade é responsável por: a) Serviço de Acolhimento Institucional, nas seguintes modalidades: - abrigo institucional; - Casa-Lar; - Casa de Passagem; - Residência Inclusiva; b) Serviço de Acolhimento em República; c) Serviço de Acolhimento em Família Acolhedora; d) Serviço de Proteção em Situações de Calamidades Públicas e de Emergências.

No Paraguai, a proteção social mantém uma perspectiva focalizada na população pobre e indígena. Mantém a semelhança dos demais países, programas de transferência de renda para a população vulnerável (situação de pobreza e idosos) e ações voltadas à redução do trabalho infantil. Desenvolve grande parte de suas ações no sentido de complementar a atenção em saúde.

No Uruguai a Proteção/Assistência Social tem sua ênfase atual na Tarjeta Uruguay Social, com vistas à transferência de recursos direcionadas principalmente para as pessoas e famílias que possuem maior dificuldade de acesso ao consumo básico de alimentação e 
outros artigos de primeira necessidade. Mantém ainda Programas relativos à questão de gênero, crianças e adolescentes, idosos.

Sobre a dimensão orgânico-ministerial ressaltam-se, ainda, as iniciativas do Uruguai para o fomento de ações cooperadas. O governo uruguaio, a partir dos acordos firmados entre Brasil e Argentina impulsionou a efetivação dos mesmos imprimindo uma nova institucionalidade à sua política de fronteira. Em 2012 o Ministério de Desenvolvimento Social (MIDES) implementou, na órbita da Dirección Nacional de Gestión Territorial (DNGT) a Unidade Temática de Fronteira (UTF). Estas Unidades foram criadas como objetivo de:

[...] aportar a la construcción de un abordaje Mides que contemple las especificidades de las regiones de frontera, identificando temas de agenda específicos y contribuyendo a la construcción de respuestas a los mismos" (MIDES \& DGNT, 2017, p. 5). Com o propósito de aplicar tal perspectiva nas suas ações, a UTF aborda temas de proteção social, em articulação com outras instituições do Estado, definindo como linhas orientadoras a promoção e o fortalecimento dos espaços de articulação binacional e o fortalecimento da representação do Mides na coordenação interinstitucional em relação a fronteiras e migrações (MONTEVIDÉU, 2017).

\section{Dimensão Substantiva ${ }^{8}$}

Um dos pontos essenciais observados a partir das entrevistas é o escasso conhecimento dos Acordos e Tratados, tanto os do MERCOSUL quanto os binacionais/trilaterais. Na esteira desta observação também pode ser lembrada a dificuldade dos entes subnacionais, com exceção da Argentina, de estabelecerem acordos formais, permanecendo a forte ênfase, em alguns municípios, de acordos informais, instituindo-se a paradiplomacia como forma de resolver demandas urgentes e inadiáveis. Entretanto há também o reconhecimento da fragilidade dos acordos informais, sujeitos a serem interrompidos face a alterações no poder local, estadual ou nacional. Esta alteração foi mencionada com frequência e indicados os retrocessos ocasionados tanto em termos locais como nacionais, produzindo interrupções de projetos de porte binacional aprovados para serem realizados nas fronteiras, que proporcionaram e proporcionariam ampliação da cidadania social, sendo referidos com ênfase pelo setor educacional na região de Santana do Livramento e Rivera.

\footnotetext{
${ }^{7}$ As indicações deste item foram retiradas exclusivamente das entrevistas com gestores e atas das Comissões de Fronteiras.
} 
Do lado da demanda da população para as áreas da saúde e assistência social transparece a questão das barreiras geográficas presentes na delimitação das fronteiras (matas, rios sem pontes, utilização de balsas para acesso aos municípios dos países vizinhos) que influenciam as opções para atendimento. Esta afirmação se confirma ao se verificar a situação de Guaíra e Salto do Guairá, pois mesmo sendo cidades gêmeas, estas não estabelecem diálogos para integração devido à dificuldade de acesso de uma cidade a outra. Neste contexto, a referência dos não nacionais para acesso à proteção social é a cidade de Mundo Novo no Mato Grosso do Sul por possibilitar acesso terrestre, e não Guaíra, no Paraná. Ainda em relação à demanda da população para as áreas objeto deste estudo, todas as cidades da linha de fronteira em maior ou menor grau atendem a população transfronteiriça dada a mobilidade pela busca de atendimento. Há, ainda, uma nova requisição a partir da corrente migratória dos últimos anos, constituída por outras nacionalidades, até então não presentes nos municípios da linha de fronteira. São migrantes de distintas nacionalidades que mantém residência passageira ou permanente nos municípios pesquisados e buscam especialmente as áreas de proteção social e saúde.

Um aspecto importante identificado é a intencionalidade presente entre os gestores em implementar as políticas de saúde, educação e proteção social na perspectiva dos direitos humanos, reconhecendo especialmente a relevância de ações educativas e protetivas. Nessa linha se identificam esforços concretos dos países na área da educação e proteção à criança e adolescente, especialmente na fronteira do Uruguai com a Argentina e Brasil. Um exemplo desta intencionalidade se evidencia nas ações de integração desenvolvidas pelas equipes responsáveis pelo encaminhamento de situações relacionadas a este público. O Instituto del Ninõ y Adolescente del Uruguay (INAU) e o Conselho Tutelar, em Rivera e Santana do Livramento, estabeleceram entre si, através de um acordo informal, "acordo de cavalheirismo" como nominado, entre os profissionais das duas instituições, que permite resolver as questões que envolvam alguma demanda da cidade gêmea vizinha.

Destacam os gestores e profissionais a importância de conhecer a organização dos Estados Parte em relação à estrutura e conformação dos sistemas de proteção social dos mesmos, no sentido de estudarem possibilidades de estabelecerem ações transfronteiriças e protocolos de atendimento. Especialmente, porque, no âmbito assistencial/proteção social há um déficit de recursos para o atendimento nas fronteiras, principalmente junto às minorias étnicas e populações vulneráveis e em situação de risco social. Este déficit é pontuado por alguns gestores afetando a capacidade de atenção à demanda relacionada as 
unidades de serviços da Proteção Social Básica tanto dos nacionais como dos não nacionais, notadamente em Santana do Livramento. A rede assistencial instalada conta atualmente com apenas dois Centros de Referência de Assistência Social, porém limitado na cobertura total de seu território, não havendo uma investigação para determinar a demanda real da área urbana e rural. Assim, devido a fragilidade da rede, os cidadãos fronteiriços, mesmo com documentação regularizada, podem não ter suas necessidades sociais atendidas pela ausência de infraestrutura do município em que reside.

Deve-se atentar, ainda, sobre a situação da população economicamente vulnerável, fortemente influenciada pelas crises econômicas e políticas vivenciadas pelos países, tanto em nível nacional como local. Tais crises alteram a dinâmica na região da fronteira e fomentam a migração transfronteiriça na busca por ações e serviços de proteção social/assistência social e saúde. Duas ordens de determinações contribuem para agravar a questão nestas duas áreas. A primeira causadora do trânsito transfronteiriço nos municípios pesquisados é a inexistência de serviços públicos de saúde para absorção desta demanda e a existência de atendimento público no município fronteiriço.

A segunda é a ausência de parâmetros para estruturação da política de assistência social em alguns dos municípios pesquisados face à inexistência de um sistema nacional que oriente e estruture esta modalidade de atenção para atendimento de particularidades que ocorrem em municípios fronteiriços. Por esta razão as ações de saúde e assistência social são fragmentadas e os serviços pulverizados, ampliando os processos de exclusão social.

Nos municípios de Foz de Iguaçu, Ciudad del Eeste, Guaíra, Salto do Guairá a questão indígena desponta como centralidade no âmbito da assistência social. Entretanto não foram identificadas ações específicas nesta área.

No setor educação, a evasão escolar foi referenciada com frequência. Embora existam ações para seu enfrentamento, ainda persistem os altos índices de evasão no ensino fundamental. Uma das explicações para o sucesso relativo destas iniciativas é a situação de extrema pobreza em que vivem as famílias, que utilizam o trabalho infantil para complementar o orçamento familiar; outro fator explicativo é a migração interna e externa há que se submetem essas famílias em busca de melhores condições de vida face as crises econômicas e políticas.

As controvérsias em relação aos critérios de acesso de nacionais e não nacionais aos serviços no campo da saúde e proteção social foram frequentes, o que sinaliza para a 
divergência entre os gestores quanto ao grau de universalidade a ser obtido, embora afirmem em plano discursivo, que o direito deve ser universal. Aparece como um indicativo para a solução desta questão, a urgência de debates e interlocuções entre os municípios favorecendo aos gestores apreender a dinâmica da organização social das fronteiras, identificando pontos comuns que poderiam viabilizar protocolos de atendimento comuns. Tal medida teria um impacto positivo entre a população demandante ao se reconhecer que esta dinâmica conforma um espaço territorial para além dos limites nacionais que integra diversos fenômenos sociais, econômicos, culturais, políticos e jurídicos.

As falas dos gestores de saúde das cidades gêmeas apontam para a predisposição para integração, ainda que seja por meio de pactos, protocolos, acordos formais ou informais para debaterem e planejarem ações conjuntas no enfrentamento e combate das endemias, surtos de doenças difíceis de serem combatidas como a dengue a leishmaniose, tuberculose, raiva, entre outras. Essa predisposição para integração é limitada pela inexistência de provisão orçamentaria para custear as ações e serviços de saúde destinados aos não nacionais, afirmação reiterada inúmeras vezes. Este fator limitante foi atenuado pela gestora de saúde de Foz do Iguaçu ao indicar estar em fase de planejamento uma Unidade de Saúde de referência para atendimento aos turistas e estrangeiros. Contrariamente, em Guaíra foi instituído a partir de 2015, o Cartão Cidadão para identificação dos nacionais residentes no município com acesso ao SUS, para diferenciá-los dos estrangeiros. Para os últimos, o Cartão SUS é bloqueado logo após o atendimento no sistema local de saúde. Situa-se, esta iniciativa, como uma estratégia para evitar a ampliação da demanda e consequente e oneração do município, inibindo o acesso aos não nacionais ao usufruto de ações e serviços de saúde não se caracterizados como urgência e emergência.

Em relação à integração na área da saúde foi mencionada a experiência iniciada pela Universidade Federal de Pelotas, que há alguns anos implantou em Santana do Livramento o Centro de Estudos do MERCOSUL por meio do Programa de Convergência Estrutural do MERCOSUL, o qual previa a instalação de um Centro de Saúde Binacional, proposta que não teve continuidade e a sede deste centro encontra-se atualmente desativada. Estas e outras iniciativas do gênero poderiam ser retomadas considerando o potencial de integração decorrente para ampliar os direitos nesta área. Como evidência de experiência inovadora na área da saúde, na mesma região fronteiriça, é a formação trilateral aos servidores brasileiros e uruguaios, através do Programa de Formação em Saúde Pública para a Área de Fronteira Brasil-Uruguai, com professores da Escola de Saúde Pública Sergio 
Arouca (ENSP/Fiocruz) e Universidad de La República do Uruguai (UDELAR). O Programa é financiado através de cooperação trilateral entre os Ministérios de Saúde do Brasil e Uruguai e Agência de Cooperação Técnica do governo alemão, com o objetivo de fortalecer serviços de vigilância em saúde e ênfase na vigilância do HIV/AIDS. A intenção, segundo a fala do gestor é construir uma Política Pública de Saúde na área da vigilância sanitária que seja adequada à realidade entre Brasil e Uruguai a ser apresentada em novembro de 2018, na Conferência Nacional de Vigilância, em Brasília e, em Dezembro, em Montevidéu.

A questão previdenciária foi mencionada com ênfase, sendo as principais questões levantadas relacionadas às diferenças burocráticas dos países, implicando em maior ou menor centralidade para resolução de situações de fronteira devido às dimensões geográficas e populacionais dos países. Como exemplo desta dificuldade, um entrevistado citou que para resolver uma situação na fronteira, no Brasil, é preciso passar por cinco instâncias de chefias, enquanto no Uruguai é encaminhada diretamente para o Banco de Previsão Social obtendo-se uma decisão final de forma rápida. Ainda em relação à Previdência Social identificou-se que o principal entrave na atenção aos usuários é a lentidão e/ou falta de regulamentação dos acordos bilaterais nos países, em que pese a melhoria ocorrida nos últimos nove anos. Mencionam, ainda, o fato do Brasil não implementar normativas para viabilizar os acordos bilaterais firmados fazendo com que, consequentemente, as pessoas vulneráveis sejam as mais afetadas. Destaca-se que esta observação não se refere unicamente à previdência social, mas também na área da saúde e proteção social, com algumas exceções. Pode-se inferir que, embora haja acordos entre os países para reger a efetivação dos benefícios de fronteiriços, percebe-se uma relativa falta de clareza sobre como, na prática, garantir os direitos previdenciários devido a grande incidência de situações com particularidades específicas, que demandariam normatizações muito detalhadas.

\section{Considerações Finais}

A relevância dos acordos, quando internalizados na ordem jurídica dos países e acompanhados de normativas nacionais que materializem os mesmos, é a sua possibilidade de atenuar as relações interpessoais observadas entre as populações fronteiriças, que "[...] são ambíguas, por vezes contraditórias, e refletem, de certa maneira, as assimetrias sociais e econômicas locais e entre os países [...]" (DESIDERÁ NETO; PENHA, 2016, p. 37). O que se 
quer afirmar é o potencial normativo dos acordos e normativas alterando padrões de comportamento não inclusivos e excludentes observados, pois conforme indicação do PEAS e do Plano de Ação para Conformação do Estatuto da Cidadania, o desenvolvimento das regiões de fronteira pode levar à diminuição das desigualdades sociais nos níveis nacional e internacional.

Um destaque significativo se refere às distintas preocupações identificadas nos relatos das Comissões de Fronteira entre Salto/Concordia e Posadas/Encarnación ${ }^{9}$. Na fronteira entre Argentina e Uruguai predominam as iniciativas no campo cultural (formação de Comissão Binacional de Esporte, Educação e Cultura para promover, coordenar e otimizar recursos), saúde (campanhas de prevenção à saúde, capacitação e jornadas bilaterais em saúde) e promoção social (economia social, fortalecimento de pequenos agricultores rurais), questões de gênero (diversidade sexual) e tráfico de pessoas, especialmente crianças e adolescentes. Na fronteira Argentina e Paraguai, Posadas/Encarnación, a preocupação central, expressa nas iniciativas propostas, é o tráfico de pessoas, a exploração sexual de mulheres e crianças e questões de segurança nacional. Indicam, com menor ênfase, a importância de ampliar as Comissões bilaterais nas áreas de saúde, trabalho e dificuldades de tramitação de documentos dos não nacionais residentes no Paraguai para acesso aos programas de proteção social.

\section{Referências}

ALUM, J. N. M.; BEJARANO, M. S. C. Sistema de Salud de Paraguay. Revista Salud Pública Paraguay, Paraguay, v. 1, n. 1, p. 13-25, 2011. Disponível em: <http://www.ins.gov.py/revistas/index.php/rspp/article/view/20/19>. Acesso em: 12 maio 2018.

BRASIL. Ministério do Desenvolvimento Social e Combate à Fome. Política Nacional de Assistência Social. Brasília: MDS, 2004.

BRASIL. Ministério do Desenvolvimento Social e Combate à Fome. Tipificação Nacional de Serviços Socioassistenciais. Brasília: MDS, 2014.

CEPAL. Institucionalidad social para América Latina y el Caribe. 2017. Disponível em: <https://dds.cepal.org/bdips/>. Acesso em: 12 maio 2018.

COSTA, V. L. C.; SILVA, P. L. B.; BIASOTO, G. (Org.). Efetividade das políticas de saúde: experiências bem-sucedidas na América Latina. São Paulo: Biruta, 2008.

\footnotetext{
${ }^{8}$ Estes relatos se referem aos dois últimos anos, em reuniões realizadas em junho de 2016 e junho de 2017.
} 
DI GIOVANNI, G.; NOGUEIRA, M. A. Dicionário de políticas públicas. 2. ed. São Paulo: UNESP/FUNDAP, 2015.

GLINOS, I. A. Cross-border collaboration. In: WISNAR, M. et al. Cross-borderhealth care in the European Union. World Health Organization/European Obsevatory on Health System and Policy. 2011. Disponível em:

<http://www.euro.who.int/_data/assets/pdf_file/0004/135994/e94875.pdf $\geq$. Acesso em: 12 maio 2018.

JIMÉNEZ, R. P.; NOGUEIRA, M. R. N. A construção dos direitos sociais e os sistemas sanitários: os desafios das fronteiras. Revista Katálysis, Florianópolis, v. 12, n. 1, p. 50-58, 2009.

LUCERO, M. F. Trabajo, pobreza y selectividad: una comparación de los diseños de intervencion del planjefas y jefes de hogary la asignacion univesal por hijo. In. LIBRO DE ACTA DEL VI CONGRESO RED ESPAÑOLA DE POLITICAS SOCIALES. Pactar el futuro: debates para un nuevo consenso en torno al bienestar. Sevilha, Universidad Pablo de Olavide, 2017. p. 648.

MARTÍNEZ, R.; VALERA, C. M. Institucionalidad y desarrollo social. In: MARTÍNEZ, R. (Ed.). Institucionalidad social en América Latina y el Caribe. Libros de la CEPAL, n. 146 (LC/PUB.2017/14-P/-*). Santiago, Comisión Económica para América Latina y el Caribe (CEPAL). 2017.

MARTÍNEZ, R. (Ed.). Institucionalidad social en América Latina y el Caribe. Libros de la CEPAL, n. 146 (LC/PUB.2017/14-P/-*). Santiago, Comisión Económica para América Latina y el Caribe (CEPAL), 2017.

MONTEVIDÉU. Ministerio de Desarrollo Social. Dirección Nacional de Gestión Territorial. Abordaje del Ministerio de Desarrollo Social para los ejes frontera y migrantes. Montevidéu: MIDES; DGNT. 2017.

DESIDERÁ NETO, W. A.; PENHA, B. As Regiões de fronteira como laboratório da integração regional no Mercosul. Boletim de Economia e Política Internacional, Brasília, n. 22, p. 33-49, jan./abr. 2016. Disponível em:

<http://www.ipea.gov.br/portal/images/stories/PDFs/boletim_internacional/160628_boleti m_internacional_22_art03.pdf >.

NOGUEIRA, V. M. R.; GIMÉNEZ, R. P.; FAGUNDES, H. S. Ampliando o Direito à Saúde: experiências de cooperação entre sistemas e/ou serviços de saúde em linhas de fronteira. Argumentum, Vitória (ES), v. 4, n.2, p. 48- 58, jul./dez. 2012.

NOGUEIRA, V. M. R. A implementação do Programa SIS Fronteiras e do Pacto pela saúde: perspectivas para a ampliação do direito à saúde aos usuários estrangeiros na fronteira Arco Sul. [S.I.], 2011. Relatório de Pesquisa. 
